\title{
Pruning reduces blister rust in sugar pine with minimal effects on tree growth
}

\author{
by Kevin L. O'Hara, Lauren A. Grand \\ and Amy A. Whitcomb
}

\section{Sugar pine trees from nine stands in two California study areas were} assessed to determine the effects of pruning on the incidence and growth of white pine blister rust. Lower limbs up to 8 feet high were removed on alternate trees. Six years following treatment, the number of infections in pruned trees was reduced compared to unpruned trees at one study area, but no blister rust was found at the other area. The results suggest that artificial pruning of sugar pine may be part of an effective, integrated strategy to maintain this species in mixedconifer California forests.

Sugar pine is an iconic species in the $\checkmark$ mixed-conifer forests of the Sierra Nevada and Cascade Range. Due to their massive size, individuals stand with a stately and elegant presence among and above their associates. In 1894, John Muir described sugar pines (Pinus lambertiana Dougl.) as "the priests of pines" and said they "seem ever to be addressing the surrounding forests" (Muir 1894). The species is also fast growing and produces valuable wood and other ecosystem amenities such as food for small mammals.

Sugar pine is a "white" or five-needle pine and part of a subgenus of the pine group that is susceptible to white pine blister rust (Cronartium ribicola J.C. Fisch). Blister rust was introduced to western North America in British Columbia in 1910 and has spread southward into the sugar pine range. This invasive pathogen has sharply reduced populations of susceptible trees across North America, including sugar pine in California and Oregon.

Treatments to limit white pine blister rust have included the physical removal of understory species in the genus Ribes, which is an alternate host for the patho-

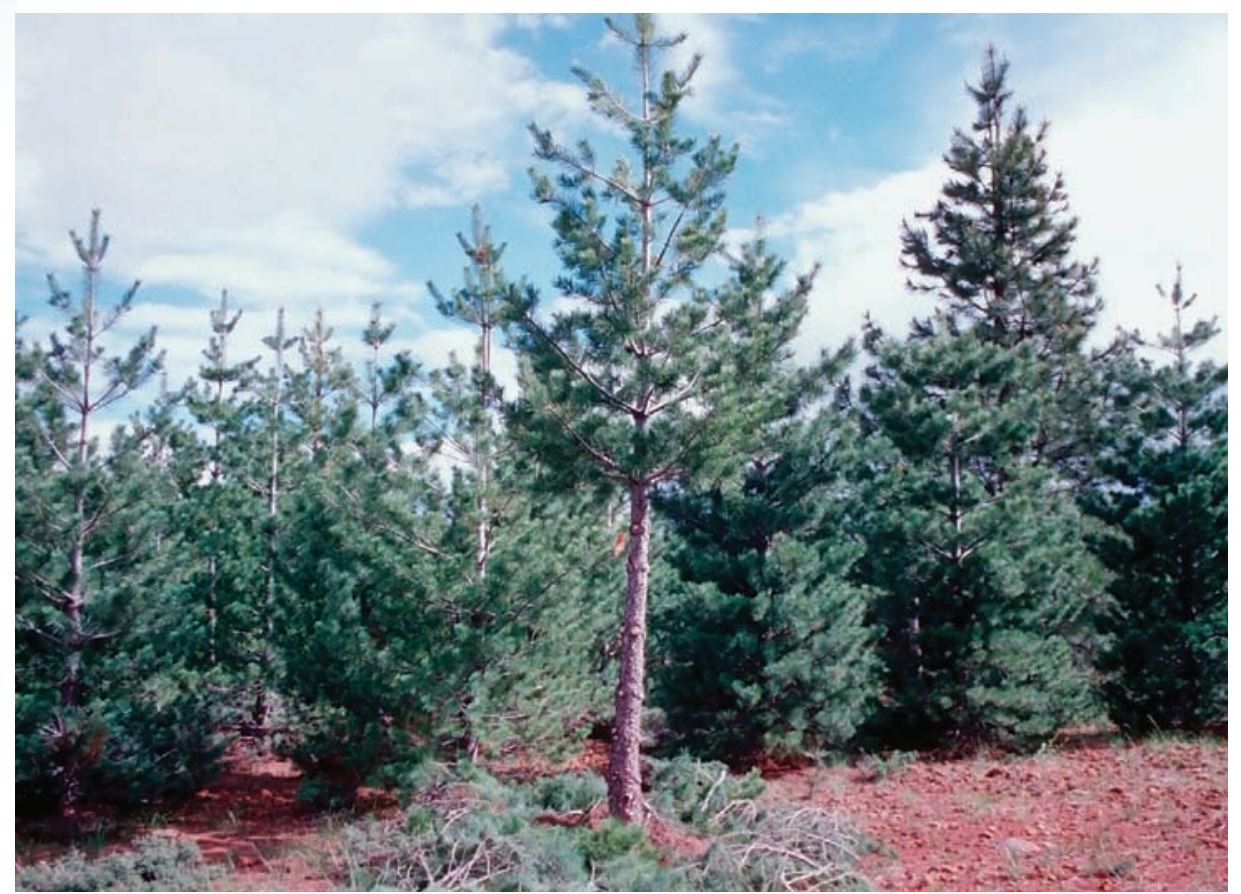

Pruning treatments were tested for their effectiveness against white pine blister rust.

gen (Maloy 1997); chemical spraying of Ribes species; and breeding of resistant sugar pine (Samman and Kitzmiller 1996). The tree-breeding efforts, which have been the most successful strategy to date, offer some promise of trees for reforestation that have an estimated $60 \%$ level of resistance to the pathogen.

However, the pathogen is also evolving, and a more virulent strain was recognized in California in 1976 (Kinloch and Comstock 1981). There are several mechanisms that allow some sugar pine to be resistant to the pathogen (Kinloch and Davis 1996). Because there is natural resistance in native populations of sugar pine and the pathogen is evolving, an integrated resistance strategy should maximize resistance in natural populations as a future safeguard (Millar et al. 1996; Samman et al. 2003).

\section{Infection process}

Trees are infected through a viable spore landing on a water droplet on a live needle fascicle or group of pine needles. The spore then germinates and infects the tree by growing through the fascicle into the inner bark of the branch or stem. Once in the stem or branch, the pathogen causes canker formation and eventually girdles the branch or stem, killing anything above the point of infection (Edmonds et al. 2000). A successful pathogen attack requires a viable spore and a living needle fascicle with moisture on it.

Viable spores typically originate from Ribes species such as currants and gooseberries and occur in highest concentrations near the ground where

\section{Artificial pruning is an accepted means of enhancing wood quality in forest trees.}

humidity is usually highest. Infections are therefore most common near the ground. For example, $85 \%$ of branch cankers in young sugar pine stands in Oregon were found within 12 feet of the ground and 97\% within 20 feet (Hays and Stein 1957). Byler and Parmeter (1979) and Smith (1996) reported similar findings in California. However, working in environments with greater fog in the southern Sierra Nevada, Kinloch and Dulitz (1990) reported greater proportions of cankers higher in trees. 
TABLE 1. Stand descriptions for sugar pine pruning treatments

\begin{tabular}{|c|c|c|c|}
\hline $\begin{array}{l}\text { Study site/ } \\
\text { stand* }\end{array}$ & $\begin{array}{c}\text { Age } \\
\text { in } 2000\end{array}$ & $\begin{array}{l}\text { Regeneration } \\
\text { harvest method }\end{array}$ & Postregeneration treatments (year) \\
\hline \multicolumn{4}{|c|}{ years } \\
\hline BFRS-141 & 10 & Clear-cut & Herbicide (1995) \\
\hline BFRS-190 & 11 & Group selection & Herbicide (1997), PCT† (1998), mastication (2005) \\
\hline BFRS-280 & 20 & Shelterwood & РCT (1995), herbicide $(1984,1989)$ \\
\hline BFRS-330 & 9 & Clear-cut & РCT (1998), herbicide (1999), mastication (2003) \\
\hline BFRS-480 & 9 & Clear-cut & РCT (1998), herbicide (1999), mastication (2003) \\
\hline BFRS-501 & 13 & Clear-cut & РСТ (1998), herbicide (1991) \\
\hline BFRS-400 & 12 & Group selection & РCT (1998), herbicide $(1992,1997)$ \\
\hline LA-75 & 25 & Clear-cut & None \\
\hline LA-86 & 14 & Clear-cut & None \\
\hline
\end{tabular}

\section{Artificial pruning}

Artificial pruning is a potentially effective means of enhancing sugar pine survival because it removes the lowermost branches where infections are most likely to occur. Previous research with eastern white pine (Pinus strobus L.) and western white pine (Pinus monticola Dougl. ex D. Don) indicated that pruning to only an 8-foot height could significantly reduce white pine blister rust infections (Weber 1964; Lehrer 1982; Hungerford et al. 1982; Hagle and Grasham 1988; O'Hara, Parent, et al. 1995; Hunt 1998). Although foresters have had some success in other white pines, and artificial pruning has been included in integrated management programs for white pine blister rust in western white pine (Hagle et al. 1989), no systematic pruning trials have been undertaken in sugar pine, and previous pruning experiments have only briefly referred to this species (Kinloch and Dulitz 1990; Kliejunas and Adams 2003).

Artificial pruning is also an accepted means of enhancing wood quality in forest trees. A typical pruning operation involves removing the lowermost live and dead branches from fastgrowing trees that have straight, highquality boles with minimal taper. After severing lower branches, trees occlude wounds, and subsequent wood formation is free of knots. This "clearwood" is therefore of higher value than wood formed without pruning. Pruning younger trees is generally most desirable as these trees can produce clearwood over a smaller defect core than older trees (O'Hara 2007). However, pruning live branches reduces a tree's photosynthetic capacity and can adversely affect tree vigor. Developing a pruning regime for sugar pine involves tradeoffs between reducing tree growth and vigor, and increasing the resistance of pruned trees to blister rust.

This study explored artificial pruning as a potentially effective means of reducing the incidence of white pine blister rust in sugar pine. The specific objectives were to: (1) assess the effectiveness of pruning on white pine blister rust incidence in sugar pine and (2) determine the consequences of pruning on sugar pine tree growth.

\section{Sierra and Cascades study sites}

Site selection. Two areas were selected because each had relatively young sugar pines in sufficient numbers to develop a study. One site was at Blodgett Forest Research Station in the central Sierra Nevada (38 $52^{\prime}$ N, $120^{\circ} 40^{\prime} \mathrm{W}$ ), and the other was near Lake Almanor in the southern Cascades $\left(40^{\circ} 19^{\prime} \mathrm{N}, 121^{\circ} 0730^{\prime} \mathrm{W}\right)$ on land owned by Roseburg Forest Products and sold to Sierra Pacific Industries during the study period.

Sites were selected and all pruning was completed early in the 2000 growing season. Sample trees were limited to 8 to 20 feet in height so that they could receive a relatively substantial pruning that might be typical of an operational pruning regime in a young stand. Seven stands, or management compartments, were selected at Blodgett forest. All had been planted in harvested openings with a mixture of conifers including both blister rust-resistant and nonresistant sugar pine; some natural regeneration had
TABLE 2. Sample sizes and numbers of infected trees by stand, 2006

\begin{tabular}{|c|c|c|c|c|}
\hline \multirow{2}{*}{$\begin{array}{l}\text { Study site/ } \\
\text { stand* }\end{array}$} & \multicolumn{2}{|c|}{ Pruned trees } & \multicolumn{2}{|c|}{ Unpruned trees } \\
\hline & Total & Infected & Total & Infected \\
\hline BFRS-141 & 27 & 6 & 26 & 7 \\
\hline BFRS-190 & 12 & 2 & 12 & 6 \\
\hline BFRS-280 & 7 & 0 & 8 & 2 \\
\hline BFRS-330 & 12 & 8 & 13 & 10 \\
\hline BFRS-480 & 23 & 7 & 27 & 9 \\
\hline BFRS-501 & 15 & 6 & 15 & 12 \\
\hline BFRS-400 & 12 & 1 & 13 & 5 \\
\hline Blodgett totals & 108 & 30 & 114 & 51 \\
\hline LA-75 & 38 & 0 & 38 & 0 \\
\hline LA-86 & 40 & 0 & 39 & 0 \\
\hline $\begin{array}{l}\text { Lake Almanor } \\
\text { totals }\end{array}$ & 78 & 0 & 77 & 0 \\
\hline
\end{tabular}

also occurred. These stands had been harvested previously with a range of regeneration methods including group selection, clear-cut and shelterwood, which leaves variable amounts of overstory cover (table 1). A combination of herbicide spraying and mechanical treatments were applied at Blodgett to control competing vegetation and reduce intertree competition. Two stands were located near Lake Almanor; both was pure sugar pine plantations planted after clear-cut harvest.

Study trees and pruning. At both sites, study trees were selected that were free of any external symptoms of white pine blister rust or any stem defects that might have been caused by animals, the formation of multiple branch leaders or

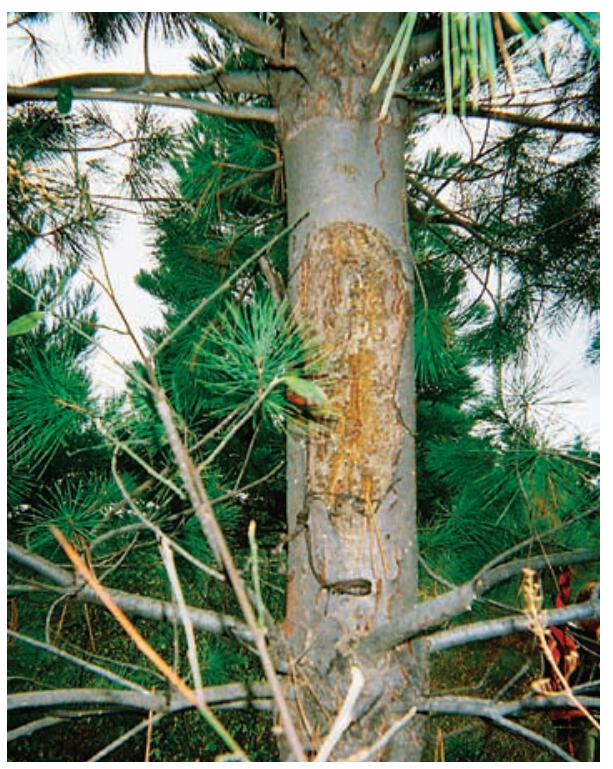

The large canker on this sugar pine at Blodgett Forest Research Station was caused by white pine blister rust, an invasive pathogen that has reduced sugar pine populations in California and Oregon. 
other disturbances. Both sites had active blister rust infections on nonstudy sugar pine trees in 2000 within the sampled stands. All of the study trees were tagged, and every other tree was pruned to a height equal to approximately a 50\% live-crown ratio - defined as the ratio of the distance from the treetop to the lowest live branch to total tree height - or no greater than 8 feet.

All needle fascicles on the stem were removed up to the pruned height to eliminate potential infection sites along the pruned stem. Branches were removed with loppers, and cuts were made as close to the stem as possible (O'Hara 2007). Pruned branches were left on the ground where they fell. Because sugar pine branches occur in whorls that can be several feet apart, pruning to a $50 \%$ live-crown ratio resulted in pruning immediately above or below a branch whorl in some cases. For these trees, the residual live-crown ratio may have been considerably more or less than $50 \%$. Control trees were the alternating unpruned trees. Both pruned and unpruned trees were selected systematically with a random start among those trees acceptable for pruning.

Measurements. After pruning, all trees were measured for total height, pruning height, diameter at breast height (dbh), and breast-height age by counting branch whorls from the treetop. Breast height was marked on all trees. Any blister rust infections that were not seen before pruning were also noted. Trees were assessed for white pine blister rust in 2003 and again after the 2006 growing season. Trees were examined for the presence of cankers on the stem or branches, and dead or flagged branches. All trees were remeasured for height and dbh after the 2006 growing season. The 2000-to2006 study period included nearly seven full growing seasons.

Statistical analysis. A chi-square test was used to assess the effect of pruning on blister rust infection for all trees. Nonparametric tests were used to assess the effectiveness of pruning because the main response is a binary variable (either presence or absence of blister rust). Logistic regression was used to assess variables such as compartment, tree size, percent live crown after pruning, and a binary variable indicating whether a tree was pruned or not.
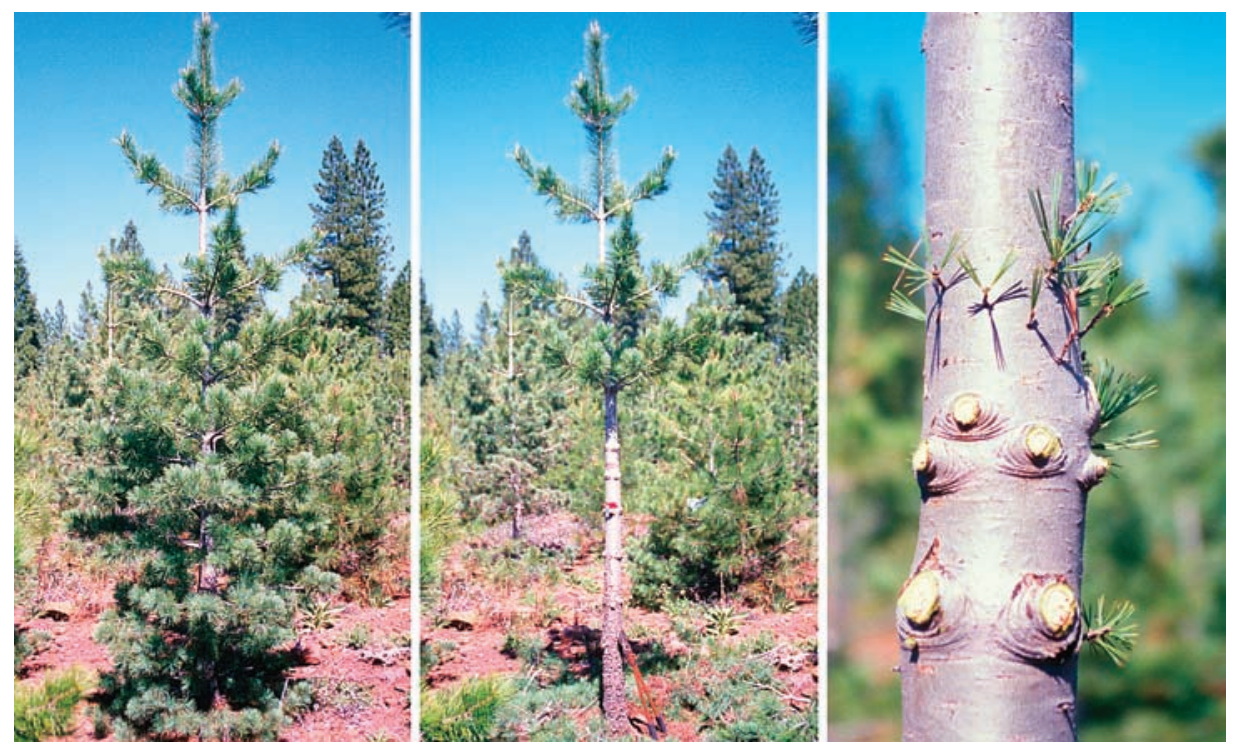

At Lake Almanor, a sugar pine, left, before pruning and, center, after being pruned to about 8 feet. Right, small branches remain above the whorl of pruned branches; these potential infection sites for white pine blister rust should be removed as part of the pruning operation.

Tree volume increment is a measurement that integrates both tree diameter and height and provides a representation of tree growth and vigor. Volumes were estimated by assuming that tree sections formed geometric solids: a cylinder below breast height, and a paraboloid from breast height to treetop. These sections were summed to total tree stem volume. Stem volume increment over the 7-year study period was the difference between volume early in the 2000 growing season and following the 2006 growing season. Tree volume was compared between pruned and unpruned trees with and without infections using analysis of variance.

\section{Effectiveness of pruning}

Mortality. Average live-crown ratio after pruning was 50.3\% at Blodgett and ranged from $32.8 \%$ to $67.1 \%$. At Lake Almanor, live-crown ratio averaged $50.6 \%$ after pruning and ranged from $38.7 \%$ to $67.6 \%$. Tree mortality was noted during both the 2003 and 2006 measurements. Eleven trees died during the study period, all of which were from stands at Blodgett, and 10 of which were pruned. Blister rust was confirmed on only one of these trees. One tree was killed in a mastication operation, and another was badly damaged by a bear. The others were possibly attacked by bark beetles or stressed by the pruning. In addition, three control trees were pruned in 2003 in a separate pruning operation. All of these trees were excluded from the volume-growth analysis.
There was no mortality in either of the Lake Almanor stands. However, 16 pruned trees in one stand were apparently attacked by bark beetles or a pitch moth shortly after pruning. These trees experienced the death of some cambium on the north side below the pruning height. None of these trees died during the study period, and all showed callus development by 2003. Four trees were not found at the Lake Almanor sites in 2006.

Blister rust infections. Blister rustinfected trees were found in all seven stands at Blodgett, but disease incidence was variable among stands (table 2). Infections were located almost exclusively on branches. Stands 330 and 501 had the greatest proportion of infected trees and stand 280, the lowest. In 2006, $46 \%$ of unpruned trees were infected with blister rust at Blodgett compared to only $26 \%$ of pruned trees. A chisquare test comparing the numbers of infected trees in the pruned and unpruned groups indicated a significantly higher frequency of infections in the unpruned trees $(P<0.0019)$. During the study period, there were no visible white pine blister rust infections in either of the Lake Almanor stands.

At Blodgett, the logistic regression model to predict presence or absence of rust indicated that the percent live crown in 2000 was a significant variable $(P<0.0001)$ but neither tree size $(\mathrm{dbh})$ nor pruning height was significant. The model included both pruned and unpruned trees, and suggested a high 


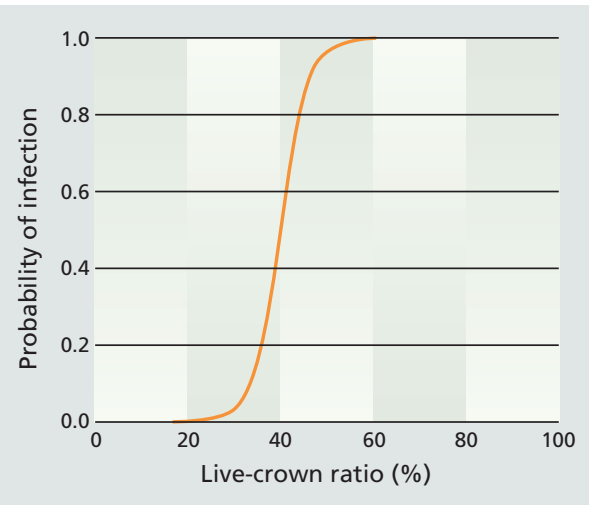

Fig. 1. Probability of infection from white pine blister rust as a function of percent live-crown ratio, based on logistic regression. The model, based on 234 observations, was significant in 2000 at $P<0.0001$.

level of significance among unpruned trees for the proximity of live branches to the ground in affecting the probability of infection (fig. 1). The resulting model was of the form:

$$
P_{i}=e^{z i} /\left(1+e^{z i}\right)
$$

where $P_{i}$ is the probability of infection, $e$ is the exponent and $z^{i}=-13.697+$ $0.343 \times$ (percent live crown)

The absence of blister rust at the Lake Almanor sites precluded a similar analysis.

Tree volume. The volume increment of individual trees averaged 2.9 square feet (ranging from 0.4 to 17.0 square feet) over the 7-year study period at Blodgett. At Lake Almanor, where trees were generally older, the average was 3.9 square feet (ranging from 0.7 to 13.6 square feet). The volume increment of pruned trees was slightly less than that of unpruned trees, but these differences were not significant in either study area (figs. 2 and 3). When trees with and without rust were compared within either pruned or unpruned groups, differences were also not significant (fig. 4). No significant patterns between relative growth rate and either posttreatment crown length or initial volume were evident for pruned trees.

\section{Managing to protect sugar pine}

The history of managing white pines such as sugar pine in the presence of white pine blister rust includes a variety of approaches to limit the damage from this exotic pathogen. Massive efforts to locally eradicate species in the Ribes genus, the primary alternate hosts

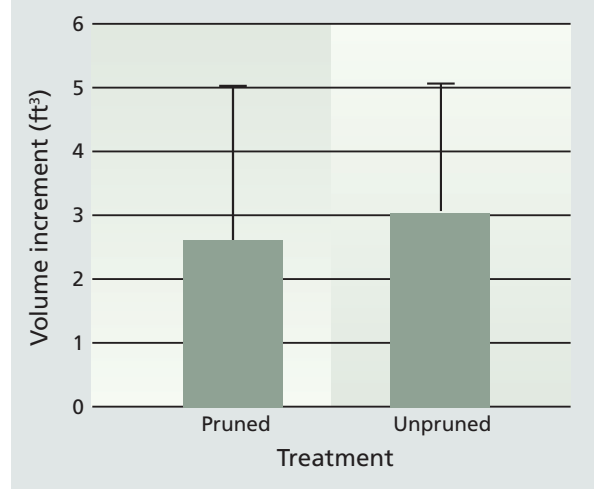

Fig. 2. Volume increment of pruned $(n=107)$ and unpruned $(n=114)$ sugar pine trees at Blodgett Forest Research Station. Differences were not significant $(P<0.1741)$. Error bars show one standard deviation.

for the pathogen, were undertaken for decades in affected regions in the western United States including California (Maloy 1997). These costly efforts were unsuccessful at controlling damage. There have also been efforts to excise stem cankers by severing the cambium around the canker, but this was considered impractical (Hagle and Grasham 1988). Efforts to breed resistant trees have shown more potential but have revealed the pathogen's ability to evolve and overcome resistance in sugar pine (Kinloch and Comstock 1981). A variety of resistance mechanisms has also been noted, reinforcing the need for a genetically diverse population of sugar pine (Kinloch and Davis 1996; Millar et al. 1996; Samman et al. 2003).

Infection rates varied significantly by stand at Blodgett (table 2). This was expected given the variety of regeneration methods used historically. This study was not designed to compare the combination of regeneration methods and pruning on infection rates, and there was insufficient data to provide meaningful comparisons. These stand differences suggest that future study of regeneration methods and microclimate effects on spore movement or production, or on Ribes frequency or vigor, may be warranted.

For example, the shelterwood treatment (stand 280) had the lowest infection rate, but the overstory trees were removed before initiation of this study. During the study period, the primary difference in stand structures between the Blodgett compartments was their size, with the group-selection unit hav-

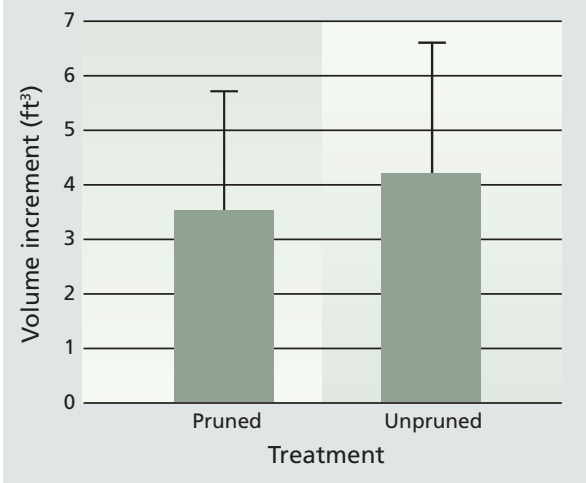

Fig. 3. Volume increment of pruned $(n=77)$ and unpruned $(n=75)$ sugar pine trees at Lake Almanor study site. Differences were not significant $(P<0.0788)$. Error bars show one standard deviation.

ing smaller openings than the others. Ironically, notes on stand 280 from the study installation in 2000 indicate that approximately $60 \%$ of the trees had lethal infections. This may be more indicative of wavelike patterns in the temporal spread of blister rust when some years have favorable environmental conditions, rather than differences attributable to stand structure.

Wave patterns of spread have been documented in the sugar pine range since 1927 (Smith 1996). The absence of rust in the Lake Almanor sites may be explained by our study period falling between wave years. It does not indicate that the pruning at Lake Almanor was unsuccessful - these trees received both the benefit of greater resistance to blister rust that may happen at any time, and the benefit of greater clearwood production.

The small but insignificant effects of pruning on tree volume increment are a logical result of reducing the photosynthetic potential of a tree. Small reductions in tree increment with low-severity pruning have been observed in a variety of conifers including Ponderosa pine (Pinus ponderosa P. \& C. Lawson) (Barrett 1968), coast Douglas fir (Pseudotsuga menziesii [Mirb.] Franco var menziesii) (O'Hara 1991) and western white pine (Pinus monticola Dougl. ex D. Don) (Helmers 1946). The height growth that occurs after pruning increases livecrown length and rebuilds the photosynthetic potential of the tree. The growth reductions following pruning are therefore greatest immediately after pruning and become smaller with time. In seven 
growing seasons following pruning, this study observed no significant growth effects. A shorter study period may have revealed significant differences. However, over longer periods such as several decades or over their lifetimes, the effect of pruning on the growth of these trees will probably be negligible.

Including artificial pruning in an integrated approach to managing sugar pine can contribute to maintaining a broad genetic base, given the success of pruning in this study and in other white pines (Lehrer 1982; O'Hara, Parent, et al. 1995; Hunt 1998). Hagle et al. (1989) included pruning as a central piece of their strategy to enhance the survival of western white pine in the northern Rocky Mountains. Artificial pruning is far from completely effective, but by increasing the probability of individual trees surviving to reproductive age or beyond, it promotes genetic diversity in surviving populations of sugar pine.

The trees in this study were pruned to no greater than 8 feet, which is probably less than optimal to increase the survival of trees. A higher pruning lift would remove additional branches that are prone to infection because of their proximity to the ground. At Blodgett, the study trees received an additional pruning lift up to $50 \%$ of the live crown, or no greater than 18 feet, during 2007. Pruning recommendations for western white pine also suggest that pruning lifts to 18 feet will provide further increases in survival (Hagle and Grasham 1988).

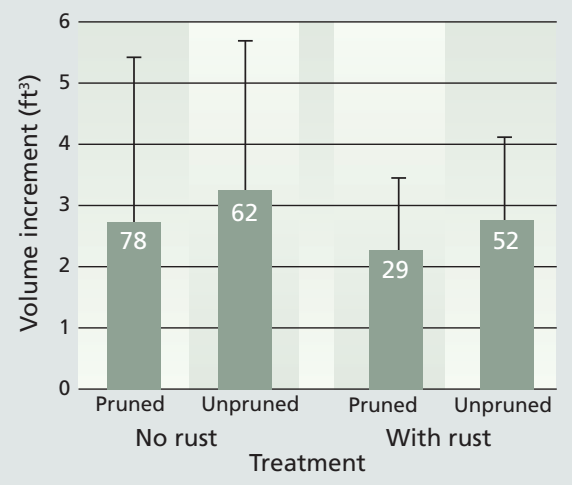

Fig. 4. Volume increment of pruned and unpruned sugar pine within groups of trees without white pine blister rust (no rust) and trees infected with rust (with rust) at Blodgett Forest Research Station. Differences were not significant within any grouping $(P<0.2430)$. Error bars show one standard deviation and numbers on bars show sample sizes.
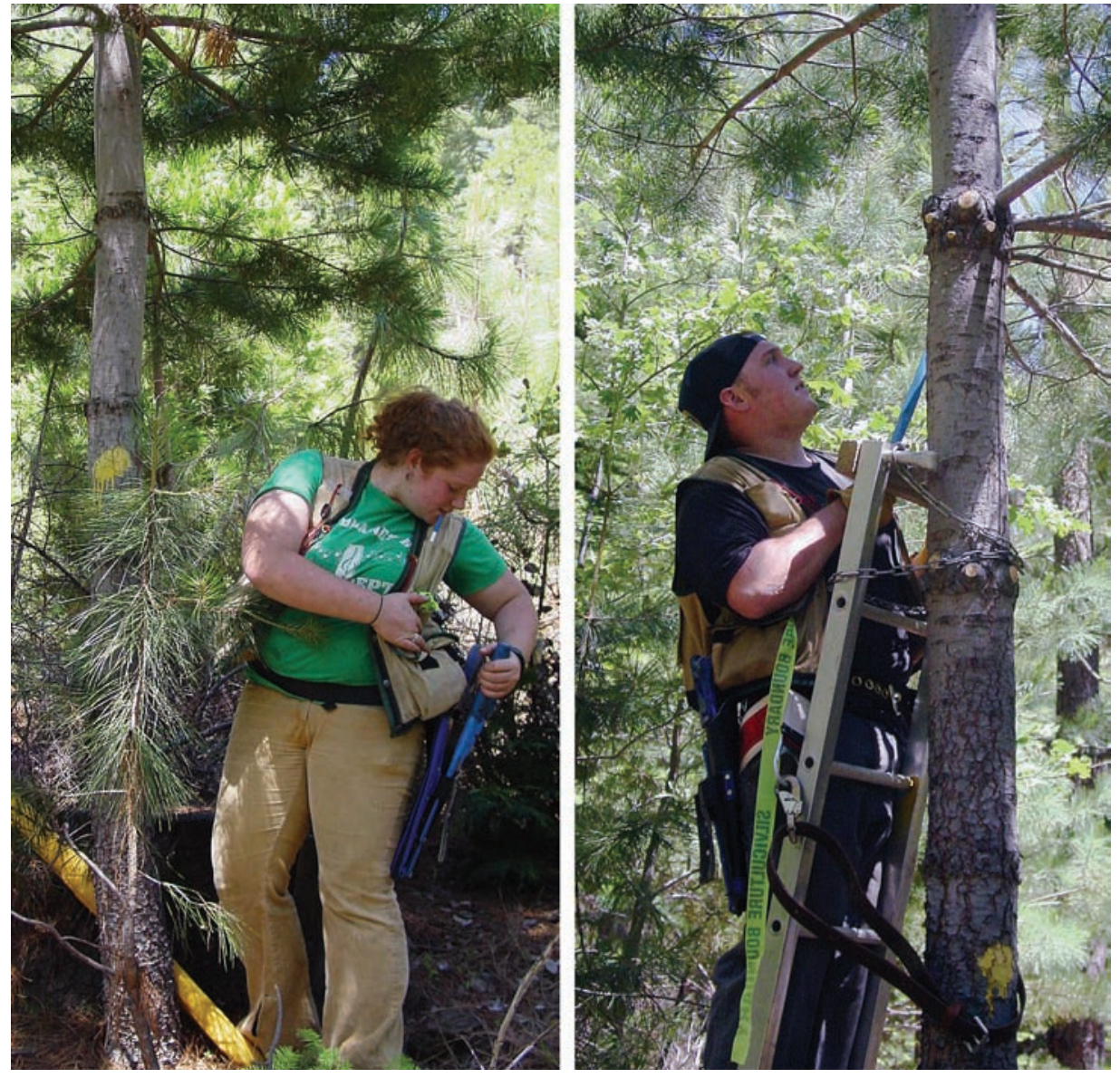

Left, at Blodgett Forest Research Station, co-author Lauren Grand prepares to prune a sugar pine. Right, field assistant Zak Thomas uses loppers and a ladder to remove a whorl of branches to a height of approximately 12 feet. A higher pruning, or pruning to the second lift, may increase an infected sugar pine's chances of survival.

\section{Pruning sugar pine to prevent blister rust}

Our management recommendations include the following:

- In production forests, pruning should focus on well-spaced trees with good form and a high likelihood of long-term survival.

- In nonproduction forests, such as on public lands, the criteria of trees with good form may be less important than selecting trees with good prospects for long-term survival.

- Eight feet represents a reasonable target pruning height for both operational reasons and blister rust control.

- Pruning should not reduce crown length by more than approximately $50 \%$ of height to maintain rapid growth rates.

- All live branches to the prescribed pruning height should be removed, including those near the ground.

- Dead branch removal is also important for meeting wood-quality objectives.

- Needle fascicles on the stem below the pruning height are potential infection sites and should be removed during the pruning operation.

- Branches with blister rust cankers greater than 4 inches from the main stem can probably be removed to prevent stem infection (DeNitto 1996).

- There is no blister rust prevention value in pruning trees with stem cankers present. 
However, a shorter pruning lift offers the opportunity to prune a tree earlier in its development, thereby providing earlier removal of potential infection sites. An appropriate pruning regime for timber production and enhancing sugar pine tree survival may therefore involve multiple pruning lifts and making the first lift as early as possible in the life of a tree. Pruning to approximately 8 feet costs about $\$ 1$ per tree for sugar pine. Pruning to 18 feet may push these costs to more than $\$ 3$ per tree, as costs increase exponentially when pruning height exceeds the height of the operator ( $\mathrm{O}^{\prime}$ Hara, Larvik, et al. 1995). A pruning regime directed toward only enhancing sugar pine survival might include pruning more trees to a shorter height, since most infections occur near the ground (Hays and Stein 1957; Hunt 1982) and the per-height-unit costs of pruning higher increase exponentially above 8 feet.

\section{Integrated strategies}

Our recommendations are to include pruning as part of integrated strategies to maintain sugar pine in ecosystems affected by white pine blister rust. Although our results are limited to several silvicultural systems on a series of similar sites in the Sierra Nevada, the success of pruning on these sites along with success in other white pine ecosystems (Weber 1964; Lehrer 1982; Hagle and Grasham 1988; Hunt 1998) suggests that pruning can be an effective tool in similar situations. Pruning in these systems will not assure the survival of any given tree, but will increase the chances of that tree reaching a reproductive age or a merchantable size (see box, page 35).

Artificial pruning of young sugar pine trees appears to be an effective integrated management tool to sustain this important species. Pruning reduced blister rust incidence in trials of three different regeneration methods at Blodgett Forest. In conjunction with the planting of genetically resistant seedlings, thinning to favor both natural and planted sugar pine, and other activities, pruning can apparently assist with sustaining sugar pine in ecosystems affected by blister rust. Additionally, artificial pruning has a negligible effect on tree growth over the first 7 years following pruning, and future effects are likely to be inconsequential.

\section{K.L. O'Hara is Professor of Silviculture, L.A. Grand is Recent Graduate, and A.A. Whitcomb is former Graduate Research Assistant, Depart- ment of Environmental Science, Policy and Man- agement, UC Berkeley.}

\section{References}

Barrett JW. 1968. Pruning of Ponderosa Pine: Effect on Growth. USDA For Serv Res Pap PNW-68. 9 p.

Byler JW, Parmeter JR. 1979. An Evaluation of White Pine Blister Rust in the Sierra Nevada. USDA For Serv Pac Southwest Region. FPM Report 79-3. $19 \mathrm{p}$.

DeNitto GA. 1996. Silvicultural methods of limiting blister rust in sugar pine. In: Kinloch Jr BB, Morosy M, Huddleson M (eds.). Sugar Pine: Status, Values, and Roles in Ecosystems. UC ANR Pub 3362. p 179-84.

Edmonds RL, Agee JK, Gara RI. 2000. Forest Health and Protection. Long Grove, IL: Waveland Pr. 630 p.

Hagle SK, Grasham J. 1988. Biological and Economic Feasibility of Pruning and Excising Western White Pines for Blister Rust Control. USDA For Serv Northern Region Pest Management, Missoula, MT. Report 88-6. 14 p.

Hagle SK, McDonald GI, Norby EA. 1989. White Pine Blister Rust in Northern Idaho and Western Montana: Alternatives for Integrated Management. USDA For Serv GTR-INT-261. 35 p.

Hays GL, Stein WI. 1957. Eliminating Blister Rust Cankers From Sugar Pine by Pruning. USDA For Serv Pac Northwest Res Stat. Res Note 151. 8 p.

Helmers AE. 1946. Effect of pruning on growth of western white pine. J For 44(9):673-6.

Hungerford RD, Williams RE, Marsden, MA. 1982 Thinning and Pruning Western White Pine: A Potential for Reducing Mortality Due to Blister Rust. USDA For Serv Res Note INT-322. 7 p.

Hunt RS. 1982. White pine blister rust in British Columbia. I. The possibilities of control by branch removal. For Chron 59:136-8.

Hunt RS. 1998. Pruning western white pine in British Columbia to reduce white pine blister rust losses: 10-year results. West J Appl For 13(2):60-3.

Kinloch Jr BB, Comstock M. 1981. Race of Cronartium ribicola virulent to major gene resistance in sugar pine. Plant Dis 65:604-5.

Kinloch Jr BB, Davis D. 1996. Mechanisms and inheritance of resistance to blister rust in sugar pine. In: Kinloch Jr BB, Morosy M, Huddleson M (eds.). Sugar Pine: Status, Values, and Roles in Ecosystems. UC ANR Pub 3362. p 125-32.

Kinloch Jr BB, Dulitz D. 1990. White Pine Blister Rust at Mountain Home Demonstration State Forest: A Case Study of the Epidemic and Prospects for Genetic Control. USDA For Serv Res Pap PSW-204. 7 p.
The authors acknowledge the assistance of those at Blodgett Forest Research Station, particularly Robert Heald and Robert York. Roseburg Forest Products and Sierra Pacific Industries provided access to the Lake Almanor field sites. Analise Elliot, Rolf Gersonde, Bruce Hammock, Patricia Peraino, Mark Spencer, Tudor Stancioui, Zachary Thomas and Rebecca Wilcox provided field assistance. John Battles, Associate Professor, Department of Environmental Science, Policy and Management, served as Guest Associate Editor for this article.

Kliejunas J, Adams D. 2003. White Pine Blister Rust in California. California Dept For Fire Prot. Tree Notes No 27

Lehrer GF. 1982. Pathological pruning: A useful tool in white pine blister rust control. Plant Dis 66(12):1138-9.

Maloy OC. 1997. White pine blister rust control in North America: A case history. Ann Rev Phytopathol 35:87-109.

Millar Cl, Kinloch Jr BB, Westfall RD. 1996. Conservation and biodiversity in sugar pine: Effects of the blister rust epidemic on genetic diversity. In: Kinloch Jr BB, Morosy M, Huddleson M (eds.). Sugar Pine: Status, Values, and Roles in Ecosystems. UC ANR Pub 3362. p 190-9.

Muir J. 1894. The Mountains of California. New York, NY: Century Co. 381 p.

O'Hara KL. 1991. A biological justification for pruning in coastal Douglas-fir stands. West J Appl For 6(3):59-63.

O'Hara KL. 2007. Pruning wounds and occlusion: A long-standing conundrum in forestry. J For 105(3):131-8.

O’Hara KL, Larvik DA, Valappil NI. 1995. Pruning costs for four northern Rocky Mountain species with three equipment combinations. West J Appl For 10(2):59-65

O'Hara KL, Parent DR, Hagle SK. 1995. Pruning eastern Cascade and Northern Rocky Mountain species: Biological opportunities. In: Hanley DP, Oliver $\mathrm{CD}$, Maguire DA, et al. (eds.). Forest Pruning and Wood Quality. Univ Washington Institute of Forest Resources. Contrib No 77. p. 216-37.

Samman S, Kitzmiller JH. 1996. The sugar pine program for development of resistance to blister rust in the Pacific Southwest region. In: Kinloch Jr BB, Morosy M, Huddleson M (eds.). Sugar Pine: Status, Values, and Roles in Ecosystems. UC ANR Pub 3362. p 162-70.

Samman S, Schwandt JW, Wilson JL. 2003. Managing for Healthy White Pine Ecosystems in the United States to Reduce the Impacts of White Pine Blister Rust. USDA For Serv Rep R1-03-118. Missoula, MT. 12 p.

Smith Jr RS. 1996. Spread and intensification of blister rust in the range of sugar pine. In: Kinloch Jr BB, Morosy M, Huddleson M (eds.). Sugar Pine: Status, Values, and Roles in Ecosystems. UC ANR Pub 3362. p 112-8.

Weber R. 1964. Early Pruning Reduces Blister Rust Mortality in White Pine Plantations. USDA For Serv Lake States Forest Experiment Station. Res Note LS-38. 2 p. 